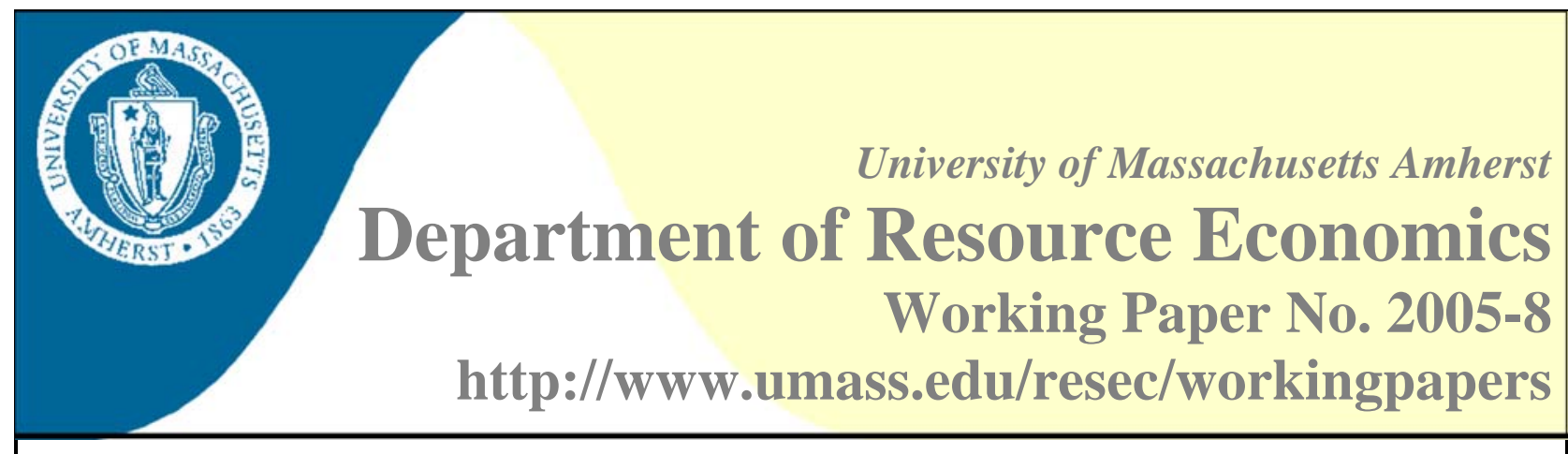

\title{
Heterogeneity and Common Pool Resources: Collective Management of Forests in Himachal Pradesh, India
}

\author{
Sirisha C. Naidu ${ }^{1}$
}

\begin{abstract}
:
In the past two decades, theoretical and empirical evidence suggests that communities of resource users are capable of overcoming social dilemmas, and are capable of creating and sustaining institutions designed to prevent degradation of common pool natural resources. However, there is incomplete understanding of what motivates this group-level behavior and why some communities are better adept at solving collective action problems than others. This paper specifically explores the role of group heterogeneity in collective action among forest communities in the northwestern Himalayas. Heterogeneity can have important social and ecological consequences and understanding both its nature and effects can help in neutralizing the negative and enhancing the positive. Based on data from 54 forest communities in Himachal Pradesh, India, this paper finds that heterogeneity has at least three dimensions: wealth, identity and interest, and each may significantly affect collective actions related to natural resource management. However, their effects are far from simple and linear.
\end{abstract}

Keywords: common pool resources, group outcomes, heterogeneity, forests

JEL Classification: D63, D71, H41, Q23, Q57

\footnotetext{
${ }^{1}$ Sirisha C. Naidu, Department of Resource Economics

University of Massachusetts, 219 Stockbridge Hall

Amherst, MA 01003-9246

E:naidu@resecon.umass.edu P: 413-545-2496 F: 413-545-5853
} 


\title{
HETEROGENEITY AND COMMON POOL RESOURCES: COLLECTIVE MANAGEMENT OF FORESTS IN HIMACHAL PRADESH, INDIA
}

\author{
Sirisha C. Naidu ${ }^{1}$
}

\begin{abstract}
:
This paper explores the role of group heterogeneity in collective action among forest communities in northwestern Himalayas. Based on data from 54 forest communities in Himachal Pradesh, India, this paper finds that heterogeneity has at least three dimensions: wealth, social identity and interest in the resource, and each may significantly affect collective actions related to natural resource management. However, their effects are far from simple and linear. The empirical results suggest that cooperation need not depend on caste parochialism, that very high levels of wealth heterogeneity can reduce cooperation, and that there can be a divergence between ability and incentive to cooperate which reduces the level of cooperation in the community.
\end{abstract}

Keywords: common pool resources, group outcomes, heterogeneity, forests

JEL Classification: D63, D71, H41, Q23, Q57

\footnotetext{
${ }^{1}$ Sirisha C. Naidu, Department of Resource Economics University of Massachusetts Amherst, 219 Stockbridge Hall Amherst, MA 01003-9246

E: naidu@resecon.umass.edu P: 413-545-2496 F: 413-545-5853
} 


\title{
HETEROGENEITY AND COMMON POOL RESOURCES: COLLECTIVE MANAGEMENT OF FORESTS IN HIMACHAL PRADESH, INDIA
}

\author{
SIRISHA C. NAIDU \\ Department of Resource Economics \\ University of Massachusetts Amherst
}

\section{Acknowledgements:}

I would like to thank Geoffrey Allen, Thomas Stevens and the Department of Resource Economics for making it possible to conduct field research, and Sandeep Minhas for his collaboration and assistance in collecting data. I gratefully acknowledge the comments and suggestions by Thomas Stevens, James Boyce, Juan Camilo Cardenas, Samuel Bowles, Panayiotis Manolakos, and members of the Environmental Working Group on earlier versions of the paper. I take responsibility for all remaining errors and omissions. 


\section{Introduction}

In dealing with the 'tragedy of the commons', the common solutions promote state or market involvement. However, the state-market solution to social dilemmas fails to recognize that individuals in a group or community interact with each other to make mutually advantageous decisions afforded to them by social institutions i.e., often they act as a group rather than as individuals and hence neither require the state nor market to increase social welfare.

This is evident in the case of common pool resources (CPRs), which are nonexcludable and rival and share properties of both public and private goods ${ }^{2}$. CPRs are often characterized by externalities and incomplete or costly contracting, and hence are prone to both market and state failures. The management of such resources therefore is likely to succeed when they are embedded in social networks. These social networks can be used to negotiate, bargain, and acquire dispersed information to monitor, retaliate and impose penalties (Bowles and Gintis, 2002).

In the last two decades, theoretical and empirical work by Acheson (1988), Baland and Platteau (1996), Berkes (1985), Chhetri and Pandey (1992), Ostrom (1990) and Wade (1988) have brought communities to the forefront of discussions of the social dilemmas associated with natural resources. They have argued and demonstrated that communities are capable of avoiding the 'tragedy of the commons' by creating and sustaining institutions to prevent degradation of natural resources. However, there is an incomplete understanding of what motivates this group-level behavior: why are some

\footnotetext{
${ }^{2}$ See McCay (1996) for a typology on goods and resources based on their characteristics, property rights and management regimes.
} 
communities better adept at solving collective action problems than others? This question has produced literature "regarding the importance or insignificance of some variables and how best to specify key relationships” (Ostrom, 1990).

In contributing to the discussion, this paper focuses on heterogeneity and its effect on collective management of forests. But heterogeneity is not unidimensional and hence three aspects are particularly dealt with - wealth, social identity, and interests. Wealth is interpreted as ability to contribute to collective action, interests reflect the incentives to contribute whereas social identity indicates the social cohesiveness of the community. In order to empirically investigate the effects of heterogeneity on cooperation, data were collected from 54 forest communities in western Himalayas in northern India. Instead of aggregating individual behavior, the paper focuses on the effects of group characteristics and institutions on aggregate outcomes. It complements theoretical modeling and the case-study approach typical in the literature on CPRs.

The paper is divided into six sections. The next section discusses the complexities of heterogeneity. It briefly reviews the treatment of heterogeneity in the literature, which primarily restricts itself to discussions of wealth and social identity. This section argues that the concepts of wealth and interest in cooperation are interchangeably used even though it may not always coincide. It suggests therefore that heterogeneity in both variables may affect cooperation differently. Section three contains a description of the 54 forest communities from which data were collected, section four discusses the empirical model, and the proxies used for the theoretical variables and section five reports the results. The paper concludes with a discussion of the results. 


\section{Complexities of Heterogeneity}

Hechter (1990) postulates that in a group, cooperation ${ }^{3}$ is determined by the extent of member obligations and the degree of compliance with these obligations; the former depends positively on the cost of producing the common good and the degree of members' interdependence, while the latter depends positively upon the monitoring and sanctioning capabilities of the group. Moreover, frequent and multifaceted social interaction among members contribute to the level of trust, generosity and otherregarding behaviors among group members and these govern both member obligations as well as monitoring and sanctioning within the group.

However, it is common for natural resources to be managed along cleavages of ethnicity, gender, religion, wealth, caste (Agrawal and Gibson, 1999) and interest in the resource (Marwell and Oliver, 1993). As a result the cost of cooperating may vary over individuals within the group. At the individual level, it affects incentives to contribute, uncertainty about preferences of others and the degree of interdependence between members. At the group level it may affect communication, monitoring and and enforcement of rules (Schlager and Bloomquist, 1996). This makes agreement on benefit and cost sharing, and prevention of free riding behavior difficult. Hence, the assumption of a homogeneous group or community is not realistic ${ }^{4}$.

Heterogeneity in social identity negatively affect cooperation under discriminatory and exclusionary norms. (Agarwal, 2001; Agrawal, 1999). Social inequities can transfer into power inequities that create a payoff differential. This

\footnotetext{
${ }^{3}$ Hechter (1990) discusses group solidarity. However, his thesis extends to cooperation or contribution to a collective good.

${ }^{4}$ Baland and Platteau (1999) contend that the issue of heterogeneity is often confused with that of group size. Small groups tend to be more effective in their monitoring and sanctioning capabilities because they are more likely to be homogeneous.
} 
decreases incentive for participation in collective action and rule compliance (Boyce, 1994). Evidence suggests that social heterogeneity negatively affects collective action (Alesina and La Ferrara, 2000; Bardhan, 2000; Bardhan and Dayton-Johnson, forthcoming; Khwaja, 2000; Molinas, 1998). Community governance in the absence of complete contracting relies on social capital. But socio-ethnic hostility and differences in power decrease the level of trust, increase problems of asymmetric information, and make regulation of collective action harder to monitor and hence less effective (Alesina, Baqir and Easterly, 1999).

Wealth heterogeneity on the other hand, has been argued to have a beneficial impact on cooperation, if users with larger endowments undertake the burden of providing the common good (Baland and Platteau, 1999; Olson, 1965; Wade, 1989). However, this result holds only under conditions of non-convexities such as fixed cost of providing for the common good, when benefits are proportional to the cooperative effort (Bardhan and Dayton-Johnson, 2000), if members with larger endowments derive returns from the resource and these returns are decreasing in the level of extraction (Baland and Platteau, 1996), or if there is a minimum threshold of cooperators and the mean level of endowment of the group is low (Marwell and Oliver, 1993).

But even under these conditions, net benefits of inequality depend on the relative magnitudes of contributions by the rich and poor users (Baland and Platteau, 1999). Higher levels of inequality provide an incentive for those with larger wealth endowments to contribute. Consequently, it provides a disincentive for poor users because their 'stake' in the common good is very small. Moreover, for a fixed amount of wealth, increasing inequality causes some users to fall below the threshold amount of wealth thereby 
rendering them unable to contribute (Dayton-Johnson and Bardhan, 1996; Marwell and Oliver, 1993).

Empirical evidence shows that wealth inequality has a non-monotonic relationship with cooperation. Bardhan and Dayton-Johnson (forthcoming) find a $U$ shaped relationship with more equal distribution of wealth are more likely to experience higher rates of conservation than those with an unequal distribution. They explain that as inequality rises, the future claims of the poor users is small, they are less likely to contribute and hence cooperation is low. But with very high levels of inequality the rich users contribute irrespective of the actions of the poor users and hence cooperation rises. The highest level of cooperation is achieved when wealth is equally distributed (and hence the claims on the resource are equally distributed) or when there is perfect inequality (when one person has claim to the entire resource).

Molinas (1998) however, in a study of 104 peasant cooperatives in Paraguay, finds an inverted $U$ relationship between inequality in endowments and cooperative performance. He explains that in highly equal communities it is possible for a coordination problem to arise since no single individual has a "differentiated incentive" to organize cooperation. The situation changes when some individuals face a higher return to cooperative behavior since it provides an incentive to organize. But when there are very high levels of inequality, there is very low incentive for cooperative action due to either the vested interests of the rich users to deter collective action for personal gain or due to seasonal migration by the poor users, which undermines the sustainability of any cooperative action undertaken by the community (Molinas, 1998) ${ }^{5}$.

\footnotetext{
${ }^{5}$ It should be noted that though the results obtained by Molinas (1998) seem contradictory to those obtained by Bardhan and Dayton Johnson (forthcoming) and Dayton-Johnson and Bardhan (2002) the former study the effect of heterogeneity on cooperation whereas the latter investigates the effect of heterogeneity on
} 
The important assumption underlying current theoretical and empirical literature pertaining to the relationship of wealth heterogeneity and cooperation is that wealth is synonymous with interest in the common good or resource, i.e., returns are increasing in the level of wealth and decreasing in the level of extraction. The collective good is an input into private production. When private wealth determines the level of production, wealth and interest in the resource are aligned. The returns to the common good in this case are increasing in the level of wealth and are decreasing in the level of extraction. Hence with higher wealth, there is a higher incentive to contribute, i.e., interest in the resource is high. However, when production is not contingent on the level of wealth as in the case of use of the natural resource for non-commercial and subsistence purposes, wealth and interests can diverge.

Wealth represents ability to contribute whereas interest represents incentives to contribute. Interest may be thought of as the value of the standard increment in the amount of good that is provided. It may be based on the desire for monetary gain, need for interpersonal support and other subjective factors that motivate human beings (Marwell and Oliver, 1993). While there is overlap in wealth and interest in the resource, in that interests may be driven by socio-economic reality (Adhikari, 2002), recognizing the differences between them is useful in constructing an empirical typology and in designing public policies with regard to redistribution.

conservation. Moreover, it is likely that Marwell and Oliver's (1993) claim that average wealth explains whether inequality is beneficial to cooperation or not may explain the different results obtained. 


\section{Data: Forests and People in the Middle Hills of Himachal Pradesh}

Data were collected from 54 forest communities in 4 regions in the Middle Hills (1000-2200 meters above sea level) of Mandi and Kangra districts in Himachal Pradesh, situated in northern India in western Himalayas.

Classified forests in India are under the sole proprietorship of the state according to the Indian Forest Act, 1927. However, Himachal Pradesh bears the distinction of being the only state in which the traditional rights of the local people have been maintained in various degrees under the colonial and post-colonial periods (Gadgil and Guha, 1995). All households in a community ${ }^{6}$ share the same use and access rights to the forest. This aspect of forest rights in Himachal Pradesh makes it conducive to use the IFRI $^{7}$ definition of user group or community as the unit of analysis. This definition does not require the group to be a formal organization, be involved in collective action or have institutionalized rules for collective decision-making. It thus allows for the analysis of why groups with the comparable rights to resources differ with respect to collective management of those resources (Poteete and Ostrom, 2003).

The economy of the surveyed communities is agropastoral and households adopt a mixture of livelihood strategies due to the rough mountainous terrain and small landholdings. Forests feature predominantly in everyday life, serving a multitude of subsistence and livelihood needs. Many within the communities depend on the forest

\footnotetext{
${ }^{6}$ The community in administrative terms may correspond to a village, hamlet, or a ward in a village. In most cases however, it corresponds to the administrative village. The local usage of the term 'community' is important because it pertains to use rights to the forest.

${ }^{7}$ The International Forestry Research and Institutions (IFRI) research program engages in comparative research on forests, institutions for forest management and people who use forest resources. IT uses the user group as a basic unit of analysis; a user group is characterized as "a set of individuals with the same rights and responsibilities to forest resources” (Poteete and Ostrom, 2003)
} 
critically due to low income and an inability to purchase substitute goods from the market.

The forests in the middle hills of the regions studied can be broadly classified into broadleaved forests in which the ban-oak (quercus incana) is the dominant species, coniferous forests which are primarily chil (pinus roxburghii) and deodar (cedrus deodara) monocultures, and mixed forests which consist of both coniferous and broadleaved trees. Broadleaved forests have significant direct use benefits. These forests provide a variety of trees, shrubs and grasses that provide fuelwood, charcoal, grass, fodder, bedding for animals, food (wild vegetables and fruits), and wood for agricultural and other implements. Moreover, ban-oak trees are evergreen and hence provide during the cold winter months as well.

The coniferous forests on the other hand, are either pinus roxberghii (chil) or cedrus deodara (deodar) monocultures. These provide fuelwood and timber but do not yield fodder nor do the leaves of the trees make for good bedding for the animals. The under story in these forests tends to be poor, thus reducing their value for grazing purposes. The pinus roxberghii specie of conifers lead to forest fires in extremely dry conditions and does not have good water retention capacity. Though conifers are very profitable commercially, for timber ${ }^{8}$ (especially the cedrus deodara) and resin (the pinus roxberghii), the Forest Department manages them as commercial ventures and the local communities do not have a claim on them.

Collective forest management is not uncommon in these regions. Seventy-eight percent of in the sample reported that they collectively managed their forests during the

\footnotetext{
${ }^{8}$ Timber from the forests is managed by the state Forest Department. Each household has a timber distribution (TD) right of one tree in 12 years subject to certain conditions. However, according to de facto rules people are allowed to cut trees under special circumstances such as marriage and funeral. The Forest Department largely respects this local custom.
} 
past ten years though only 63 percent still exist. Collective management takes the form of meetings to discuss issues concerning the forest, and activities related to maintenance, administration, forest protection and monitoring. Maintenance of the forest includes regeneration of the forest such as planting trees and fencing parts of the forest. Administrative activities involve meeting with forest officials on institutional matters, forest protection concerns itself with fire fighting and prevention activities, and monitoring involves ensuring that the rules set by the institution are not violated and that violations are penalized. Communities may engage all or a few of these activities depending on the perceived need for them.

External agencies (such as the Himachal Pradesh State Forest Department and NGOs) have been encouraging collective management. Forty-five percent of the sampled communities reported receiving some form of assistance from external agencies; 37 percent of these were established at the sole discretion of the external agency and the remainder were established by community members and the external agency. Assistance however, is not restricted to setting up the institution and helping to overcome the firstorder collective action problem. In some cases, it extends to decision making on administrative and forest management, rule violation, and imposing fines on noncompliance.

With the aid of local administrators, NGOs and others familiar with the regions, a sampling frame was determined consisting of communities that a) are situated in the Middle Hills (1000- 2200 meters above sea level) regions of the four watersheds, b) that do not engage in commercial extraction of forest resources, and c) are not conflictridden. Communities were chosen at random from this list. It is unlikely that this list was 
exhaustive though an effort was made to minimize selection bias. The data primarily serve to test the theoretical assertions about heterogeneity and its implications.

\section{Cooperation and its Determinants}

The determinants of cooperation can be classified into five categories based on work by Agrawal (2001), Baland and Platteau (1996), Marwell and Oliver (1993), Ostrom (1990) and Wade (1988). These categories are resource characteristics, (forest type, state of the forest, legal category of the forest), group characteristics (household size, group heterogeneity), relationship between user and resource (dependence), institutional arrangement and external environment (external intervention, nonfarm income); they form the basis for the conceptual model (see Fig. 1).

One of the criticisms of CPR theory is that it defines outcomes as "success" or "failures" which raises questions about its normativity (Steins and Edwards, 1999). Therefore, the dependent variable, degree of cooperation (coop) is constructed by applying principal components analysis (PCA) to characteristics of collective forest management as practiced in the communities. These characteristics include the period of existence of the institution, proportion of households that attend meetings, and the presence of four forest related activities of forest maintenance, administration, forest protection and monitoring. 


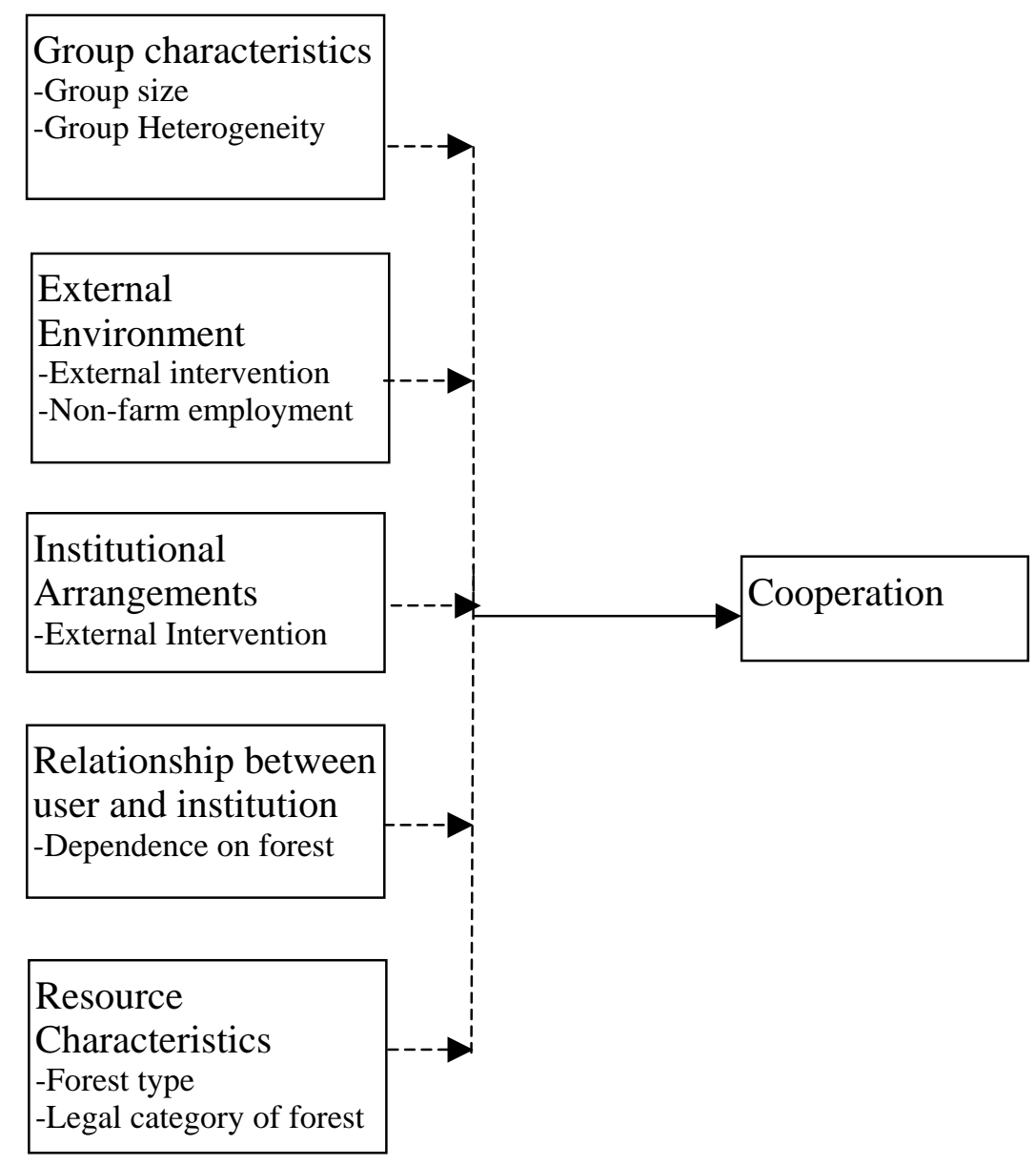

The period of existence of the institution (exist) is indicative of the sustainability of the institution and the turnout at the forest related meetings reflects the involvement of community members (meetings). The institutional activities of maintenance, administration, protection and monitoring represent labor, time and monetary contributions by the members. Given the constraints of the study period, it was not possible to collect information on the manhours spent on each of these institutional activities and hence each is represented as a dummy variable. Since these components 
constitute collective management of forest resources, they are correlated with each other (see Table 1 for the correlation coefficients).

Table 1: Correlation Coefficients*

\begin{tabular}{|c|c|c|c|c|c|c|}
\hline & Existence & Meetings & Monitoring & Protect & Administration & Maintenance \\
\hline Existence & 1 & & & & & \\
\hline Meetings & $\begin{array}{l}-0.17 \\
(.21)\end{array}$ & 1 & & & & \\
\hline Monitoring & $\begin{array}{l}-0.40 \\
(.002)\end{array}$ & $\begin{array}{l}0.58 \\
(<.0001)\end{array}$ & 1 & & & \\
\hline Protect & $\begin{array}{l}-0.42 \\
(0.002)\end{array}$ & $\begin{array}{l}0.66 \\
(<.0001)\end{array}$ & $\begin{array}{l}0.89 \\
(<.0001)\end{array}$ & 1 & & \\
\hline Administration & $\begin{array}{l}-0.25 \\
(0.06)\end{array}$ & $\begin{array}{l}0.51 \\
(<.0001)\end{array}$ & $\begin{array}{l}0.46 \\
(0.00)\end{array}$ & $\begin{array}{l}0.43 \\
(.001)\end{array}$ & 1 & \\
\hline Maintenance & $\begin{array}{l}-0.24 \\
(0.08)\end{array}$ & $\begin{array}{l}0.31 \\
(0.02)\end{array}$ & $\begin{array}{l}0.35 \\
(0.01)\end{array}$ & $\begin{array}{l}0.41 \\
(.002)\end{array}$ & $\begin{array}{l}0.62 \\
(<.0001)\end{array}$ & 1 \\
\hline
\end{tabular}

* The figures in parentheses denote the $p$-values.

The PCA approach was adopted because each of the individual components described here does not adequately reflect cooperation. For example, some communities which do not hold meetings since forest-related rules are well-established and there are few conflicts. In other communities, maintenance and administration are predominant either due to their association with the Forest Department or if the forests are degraded enough to justify efforts towards its regeneration.

The first principal component explains 0.57 of the total variation in the data. This is used as the dependent variable, (coop); it represent the degree of cooperation that exists with respect to forest management. The final construct (coop) is calculated based on 
scoring coefficients. The statistical procedure standardizes the variable and hence the final construct, coop takes a value between -1.41 and 1.51 , and has a mean of zero and a standard deviation of one. Table 3 gives the factor loadings which shows how each variable is correlated with the final construct.

Table 2: Correlation with Index of Cooperation

\begin{tabular}{ll}
\hline Components of Collective Management & Factor Loadings \\
\hline Existence & 0.66 \\
Meetings & 0.79 \\
Monitoring & 0.88 \\
Protect & 0.9 \\
Administration & 0.69 \\
maintenance & 0.59 \\
\hline
\end{tabular}

In the sampled communities use and access to the forest are open to all in the community and are not determined by wealth ${ }^{9}$ Hence, wealth and ability to contribute do not necessary reflect interest and incentives to contribute to collective action. Thus. it would be appropriate to treat wealth differently from interest. It also follows that differences in wealth should be treated differently from differences in interest.

\footnotetext{
${ }^{9}$ One could argue that wealthy users have access to better technology and hence can extract more. But this is not the case for subsistence direct use consumption of forest products in Himachal Pradesh.
} 


\begin{tabular}{|c|c|}
\hline Coop & $\begin{array}{l}\text { The dependent variable. It is the index of cooperation as described } \\
\text { above. It is calculated based on the characteristics of collective } \\
\text { management of forests in the community. }\end{array}$ \\
\hline Hh & $\begin{array}{l}\text { It denotes group size and is the number of households in the } \\
\text { community }\end{array}$ \\
\hline Social_heter & $\begin{array}{l}\text { A proxy for heterogeneity in social identity. It measures the } \\
\text { probability that no two households belong to the same caste. }\end{array}$ \\
\hline Socialsq & The square of social_heter. \\
\hline Wealth_diversity & $\begin{array}{l}\text { A proxy for wealth heterogeneity and indicates ability to contribute } \\
\text { to collective management. It is calculated based on Greenberg's B } \\
\text { index to measure diversity in landholdings of households in the } \\
\text { community. }\end{array}$ \\
\hline Wdiversq & The square of wealth_diversity. \\
\hline Interest_heter & $\begin{array}{l}\text { An indicator for interest heterogeneity. Measures the diversity in } \\
\text { intensity of dependence on the forest across households in the } \\
\text { community based on Greenberg's B index. }\end{array}$ \\
\hline Interest_diver & $\begin{array}{l}\text { The interaction term between wealth_diversity and interest_heter. } \\
\text { Measures the conditional effect of the two variables. }\end{array}$ \\
\hline Outside & $\begin{array}{l}\text { An alternate indicator for interest heterogeneity. Measures } \\
\text { heterogeneity in outside options. }\end{array}$ \\
\hline Outside_diver & $\begin{array}{l}\text { The interaction term between wealth_diversity and outside. } \\
\text { Measures the conditional effect of the two variables. }\end{array}$ \\
\hline Prop_nonfarm & $\begin{array}{l}\text { Measures the proportion of the population that has nonfarm sources } \\
\text { of income. It is a proxy for outside options. }\end{array}$ \\
\hline Index_extint & It is the index of external intervention. \\
\hline Avgprop_use & Measures the extent of dependence on the forest. \\
\hline Broad_f & Dummy variable for broadleaved forests \\
\hline Mixed_f & Dummy variable for mixed forests. \\
\hline Legal_upf & $\begin{array}{l}\text { Dummy variable for undemarcated protected forests. It denotes the } \\
\text { legal category of the forest. }\end{array}$ \\
\hline
\end{tabular}

Heterogeneity in social identity is proxied by social_heter. It measures the probability that no two households belong to the same caste ${ }^{10}$. This measure is the inverse of the Hirschman-Herfindahl concentration index (Laitin, 2000). Social_heter has a mean of 0.26 (see Table 4) for the surveyed communities which means that on average, 74 percent of the community belongs to the same caste ${ }^{11}$. It is expected that if heterogeneity in social identity makes agreement and sharing of the benefits and costs of

\footnotetext{
${ }^{10}$ There may be other categories that people in these communities identify with such as occupation and gender though these are not explored in this paper.

${ }^{11}$ In other caste-based societies in India, caste is highly correlated with wealth and power. In the sampled communities the correlation between wealth and social heterogeneity is positive and statistically significant but low at 0.24 .
} 
collective action much harder then social_heter will have a negative effect on cooperation.

Wealth heterogeneity is calculated modifying Greenberg's B index (Greenberg, 1956; Laitin, 2000) such that the wealth heterogeneity index equals:

$$
\text { wealth_diversity }=\sum_{m n}(m n)\left(r_{m n}\right)
$$

where $\mathrm{M}$ and $\mathrm{N}$ are any two landholding categories ${ }^{12}, m$ and $n$ are the proportions of households in landholding categories $\mathrm{M}$ and $\mathrm{N}$, and $r_{m n}$ is the weight assigned.

When $\mathrm{M}$ and $\mathrm{N}$ are the highest and lowest landholding categories, $r_{m n}$ takes the value 2 , otherwise it takes the value $1^{13}$.

This variable may be considered endogeneous if better cooperation in forest management leads to higher wealth. However, in the surveyed communities, land is typically inherited and the market for land is quite thin. Hence it can be treated as an exogenous variable.

Wealth_diversity has a positive effect if differential levels of wealth increase the levels of contributions to the common good. This is hypothesized to be true when the mean level of wealth is very low. However, if the mean level of wealth is high, then increasing wealth heterogeneity can decrease ability to contribute and lead to lower levels of cooperation. It is thus likely that wealth_diversity will have a non-monotonic relationship with cooperation.

Heterogeneity in resource-dependence reflects heterogeneity in incentives to contribute and hence it is used as an indicator of interest heterogeneity. This variable interest_heter is constructed using Greenberg's B index (see Laitin, 2000) based on three

\footnotetext{
${ }^{12}$ Households in a community fall under one of the following landholding category: below 1 acre (10 kanals), between 1- 2.5 acres (10 and 25 kanals) and above 2.5 acres (25 kanals).

${ }^{13}$ This is done in order to emphasize the difference between the lowest and highest landholding categories and not treat them symmetrically.
} 
categories indicating the intensity of resource-dependence ${ }^{14}$. As with the measure for wealth heterogeneity, the distance between the zero dependence and critical dependence categories is weighted twice as much as the distance between the other categories in order to emphasize the difference between the former. Heterogeneity in dependence can lead to a divergence in preferences regarding resource management. This can lead to different weights being attached to the future state of the resource and can influence the degree of contribution or involvement in collective management (see Baland and Platteau, 1999; Kant, 2000) ${ }^{15}$. Hence, it is hypothesized that this variable will negatively affect cooperation.

The interaction term, interest_diver captures the effect of wealth heterogeneity conditional on the existence of heterogeneity in dependence and vice versa. The effect of this term is indeterminate a priori. The interaction term will positively affect cooperation if ability to contribute influences interest in the resource. However, if there is a divergence between ability and interest, then the interaction term will negatively affect cooperation.

Outside and outside_diver are used as alternate indicators for interest heterogeneity and its interaction with wealth heterogeneity. Outside measures heterogeneity in the outside options of the community, in other words, heterogeneity in the sources of employment that are accessed by the people of the community. Under the presence of alternative employment opportunities, households and individuals have the option of weighing returns from the resource relative to returns from the alternative employment. This affects interest in the resource and changes the incentive to contribute

\footnotetext{
${ }^{14}$ Households in a community were classified based on the intensity of dependence on the forest as: proportion that are critically dependent, proportion that uses the forest but has access to substitutes, and ${ }_{15}$ roportion that has zero dependence.
} 
to collective efforts to manage and conserve the resource. Lucrative earning opportunities that fall outside the domain of the resource can significantly affect incentives to cooperate, availability of labor and social cohesion within the community that promotes cooperative behavior (Bardhan and Dayton-Johnson, 2000).

Outside is calculated as the probability that no two individuals fall under the same category. Correlation between outside and social_heter, and wealth_diversity is not statistically significant. A rise in this probability, i.e., in the heterogeneity of outside options is expected to increase the divergence in the preferences and interests of those who make up the community with regard to management and conservation of the forest and hence it is expected to affect cooperation negatively.

Outside_diver is the interaction term between wealth heterogeneity and heterogeneity in outside options. The effect of the interaction term is indeterminate $a$ priori. If land poor households are those with access to outside options, then it could either increase cooperation if it implies that it increases the ability of the poor households to contribute; if it implies that it decreases the time horizon of those with access to outside options, it can decrease cooperation. If however, land wealthy individuals are also the ones with access to outside options, it could negatively affect cooperation.

The economic contribution of environmental resources to the welfare of rural households is highly significant (Cavendish, 2000; Jodha, 1995, 2002; Reddy and Chakravarthy, 1999). Moreover, since communities use the forest predominantly for subsistence purposes, it is expected that this use of the forests is likely to prompt households to cooperate with each other to achieve better management and yield of these forest products. Hence avgprop_use is expected to have a positive effect on collective action. 
Table 4. Univariate statistics of the variables

\begin{tabular}{llllll}
\hline Label & Variable & Mean & Std Dev & Min & Max \\
\hline Coop & Index of cooperation & 0 & 1.000 & -1.407 & 1.505 \\
Hh & Group size & 85.852 & 115.731 & 17.00 & 550.000 \\
Social_heter & Social heterogeneity & 0.264 & 0.223 & 0 & 0.647 \\
Socialsq & Social heterogeneity squared & 0.119 & 0.125 & 0 & 0.418 \\
wealth_diversity & Wealth heterogeneity & 0.416 & 0.229 & 0 & 0.922 \\
Wdiversq & Wealth heterogeneity squared & 0.224 & 0.203 & 0 & 0.849 \\
interest_heter & Dependence heterogeneity & 0.304 & 0.260 & 0 & 0.936 \\
interest_diver & Interaction between wealth & 0.137 & 0.144 & 0 & 0.585 \\
& $\begin{array}{l}\text { heterogeneity and dependence } \\
\text { heterogeneity }\end{array}$ & & & & \\
Outside & Heterogeneity in outside options & 0.154 & 0.119 & 0 & 0.488 \\
outside_diver & Interaction between wealth & 0.064 & 0.054 & 0 & 0.256 \\
& $\begin{array}{l}\text { heterogeneity and heterogeneity in } \\
\text { outside options }\end{array}$ & & & & \\
Prop_nonfarm & Proportion with non-farm income & 0.099 & 0.111 & 0 & 0.611 \\
Index_extint & External intervention & 1.036 & 1.621 & 0 & 6.000 \\
avgprop_use & Average proportional use & 0.485 & 0.265 & 0 & 1.000 \\
\hline
\end{tabular}

Frequency For Dummy Variables

\begin{tabular}{llll}
\hline Label & Variable & Frequency & Percentage \\
broad_f & Broadleaved forest & 9 & 16.46 \\
mixed_f & Mixed forest & 32 & 58.18 \\
legal_upf & $\begin{array}{l}\text { Legal category- Undemarcated } \\
\text { Protected Forest }\end{array}$ & 17 & 30.91 \\
\hline
\end{tabular}

The other variables are included in the regression analysis to control for their effects on cooperation. Table 3 concisely describes the dependent and explanatory variables used and Table 4 gives the univariate statistics for these variables. 


\section{Econometric Results}

Table 2 reports the econometric results. The variance inflation factors indicate no multicollinearity with the exception of the squared terms. White's test and Breusch-Pagan tests for heteroskedasticity were unsuitable for these data due to the large number of dummy variables, but the LM and Q tests suggest constant variance ${ }^{16}$.

Social heterogeneity exhibits a $U$-shaped relationship with cooperation. It is highly significant (at the 1 percent level) in specification 2 and mildly significant (at the 10 percent level) in the other two specifications. It suggests that cooperation is high when the community is completely homogeneous and when its highly heterogeneous but moderate levels of social heterogeneity are not conducive to cooperation. The turning point for this quadratic function is 0.31 for the first two specifications and 0.3 for specification 3.

Social heterogeneity is the probability that no two households in the community belong to the same caste. When this probability is equal to zero, it implies that all households in the community belong to the same caste and there is homogeneity in social identity. Communication and interaction among households within the community is likely to be high (or at least is not impeded due to social reasons); hence it is not surprising that cooperation is high.

\footnotetext{
${ }^{16}$ Since the dependent variable coop is censored, tobit models were run on the two specifications. The tobit results were found to be similar to OLS results leading to the conclusion that data censoring does not pose a problem. Hence the OLS results are equally valid and are presented in Table 2.
} 
Table 2. Regression Results

Dependent Variable: Coop

\begin{tabular}{|c|c|c|c|}
\hline & Specification 1 & Specification 2 & Specification 3 \\
\hline Intercept & $-1.89 * * *$ & $-2.33 * * *$ & $-2.23 * * *$ \\
\hline Hh & -0.0001 & -0.001 & -0.0002 \\
\hline Social_heter & $-2.94 *$ & $-4.51 * * *$ & $-2.98 *$ \\
\hline Socialsq & $4.63 *$ & $7.34 * * *$ & $4.99 *$ \\
\hline Wealth_diversity & $3.18 *$ & $5.99 * * *$ & 3.06 \\
\hline Wdiversq & $-4.40^{* *}$ & $-7.12 * * *$ & -2.53 \\
\hline Interest_heter & & 0.94 & \\
\hline Interest_diver & & $-3.72 *$ & \\
\hline Outside & & & 4.13 \\
\hline Outside_diver & & & $-10.41^{*}$ \\
\hline Prop_nonfarm & -0.96 & -1.21 & -1.4 \\
\hline Index_extint & 0.04 & 0.05 & 0.01 \\
\hline Broad_f & 0.53 & $0.71 *$ & $0.69 *$ \\
\hline Mixed_f & 0.37 & 0.33 & 0.53 \\
\hline Avgprop_use & $2.66 * * *$ & $2.71 * * *$ & $2.58 * * *$ \\
\hline Legal_upf & $0.80 * * *$ & $0.85 * * *$ & $0.71 * * *$ \\
\hline $\mathbf{R}^{2}$ & 0.68 & 0.74 & 0.72 \\
\hline Adjusted $\mathbf{R}^{2}$ & 0.582 & 0.64 & 0.61 \\
\hline $\mathbf{F}$ & 6.96 & 6.93 & 6.55 \\
\hline
\end{tabular}


The problem arises when the community is composed of more than one caste group. While caste based social inequities are less common in these parts of the country, caste loyalty is a prominent feature which drives social interactions within communities. At low levels of social heterogeneity (when the probability that two households do not belong to the same caste is low), a majority of households in the community belong to one particular caste group. While interaction among households from the majority caste may be high, households from the minority caste groups may be viewed as 'outsiders'. This could result in social discrimination and exclusion from the decision-making process and hence lower participation in collective management process from the latter.

However, the statistically positive squared term suggests that a socially heterogeneous community need not necessarily face lower levels of cooperation. When the probability that two households do not belong to the same caste increases to more than 30 percent, then cooperation is higher ${ }^{17}$. Cooperation is the highest when the proportion of households across each caste is equal (i.e., when the community is completely heterogeneous). This can be interpreted to mean that under such a case, the possibility of domination by any one caste group is lower. This decreased ability to capture power in the community perhaps increases the possibility of higher interaction, higher communication and trust levels and hence higher levels of cooperation on issues of common concerns such as forests.

The results show that social homogeneity is not a pre-requisite to cooperation and that the inherent problem is not necessarily the degree of social heterogeneity but what it implies for the marginal sub-groups in the community. High levels of cooperation

\footnotetext{
${ }^{17}$ In 50 percent of the sampled communities, social heterogeneity is higher than 0.3 .
} 
may be achieved in socially heterogeneous communities if exclusion and discrimination are minimal.

Wealth heterogeneity shows an inverted $U$-shaped relationship with cooperation. Wealth heterogeneity is measured by diversity in landholdings across households in the community and is interpreted as heterogeneity in ability to pay. The coefficients of wealth_diversity and wdiversq are mildly significant in specification 1, highly significant in specification 2, and statistically insignificant in specification 3; but the signs of the coefficients do change across specifications.

The results show that cooperation is low when there is perfect homogeneity and perfect heterogeneity in landholdings across households in the community. In specification 1, the highest degree of cooperation is exhibited at the turning point of 0.36 . Fifty four percent of the sampled communities are likely to increase cooperation as long as the index of wealth heterogeneity does not increase 0.36 . For the remaining 46 percent of the surveyed communities that experience wealth heterogeneity greater than 0.36 , cooperation is likely to decline if heterogeneity increases. The highest degree of wealth heterogeneity occurs when 50 percent of households in the community are in the lowest and highest landholding category each.

The results suggest that for a fixed amount of wealth ${ }^{18}$ in the community, small levels of wealth heterogeneity positively affects cooperation. So transferring wealth from non-contributors to contributors increases the level of collective action. This supports Olson's (1965) claim that inequality increases the level of provision of the collective good.

\footnotetext{
${ }^{18}$ Land is used as a proxy for wealth; there is a fixed amount of land in each community.
} 
However, the statistically significant squared term for the index of wealth heterogeneity suggests that this holds only for low levels of inequality. When the index of wealth heterogeneity increases above 0.36 , cooperation within the community declines. At very high levels of wealth heterogeneity, a significant proportion of the households in the community is below a threshold level of wealth rendering them unable to contribute to collective action. Households below this threshold are more likely to engage their labor in activities that yield private gain, i.e., they are more likely to spend a higher proportion of their time as migrant or casual laborers than in participating in collective action. Since cooperation depends on labor contributions, this means that high levels of wealth heterogeneity lowers the level of cooperation within the community.

Heterogeneity in resource-dependence, interest_heter which is an indicator of heterogeneity in interests is statistically insignificant but its interaction with wealth heterogeneity, interest_diver is negative and statistically significant at the 10 percent level. Controlling for wealth heterogeneity, heterogeneity in resource-dependence does not affect cooperation; the relative effects of interest heterogeneity do not statistically explain the level of cooperation.

However, conditional on the presence of wealth heterogeneity, heterogeneity in resource dependence, decreases the level of cooperation. The negative, mildly significant coefficient of interaction between heterogeneity in wealth and resource-dependence indicates that there is a divergence between ability to contribute and incentives to contribute and this divergence decreases participation in collective management. This means that when those with the highest incentives to cooperation (i.e., those who depend of the resource) are not those with the ability to contribute, then cooperation is low. 
Under the presence of heterogeneity in resource dependence, wealth heterogeneity maintains its $U$-shaped relationship with degree of cooperation but the turning point is lower at $0.34^{19}$. This means that when wealth heterogeneity rises greater than 0.34 , cooperation starts to decline. Figure 2 uses the estimated coefficients of variables wealth heterogeneity, heterogeneity in resource-dependence and the interaction term between the two dimensions of heterogeneity to show the relationship of the variables with cooperation. It shows the inverted $U$-shaped relationship between cooperation and wealth heterogeneity and that under the presence of wealth heterogeneity, heterogeneity in resource-dependence decreases the level of cooperation.

Figure 2: Plot of Estimated Coefficients of Wealth Heterogeneity, Interest Heterogeneity and the Interaction between Wealth and Interest Heterogeneity

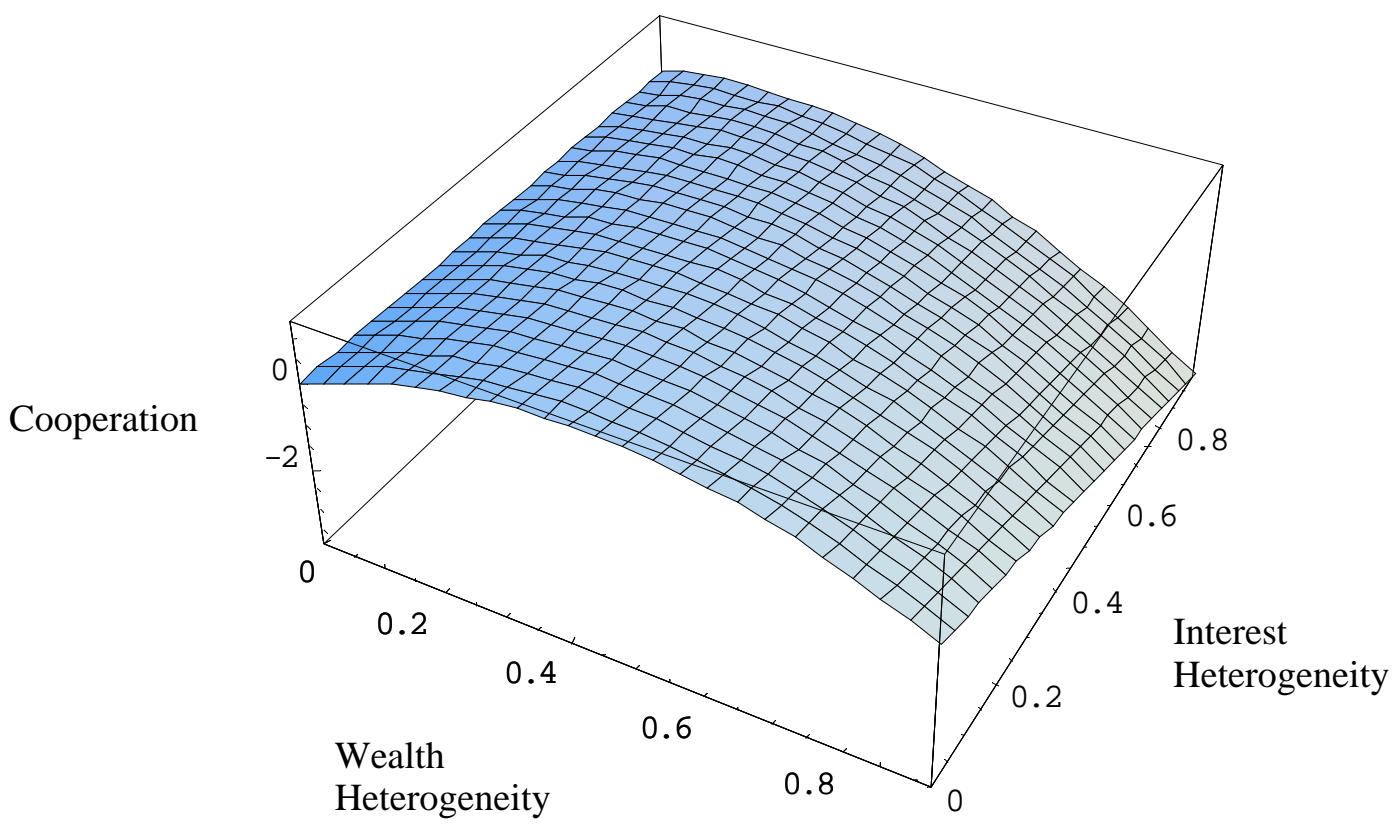

${ }^{19}$ The turning point is obtained by evaluating at the mean of dependence heterogeneity. 
Specification 3 substitutes heterogeneity in outside options for heterogeneity in resource-dependence as an indicator for interest heterogeneity. Under this specification, the coefficients of wealth heterogeneity and its square become statistically insignificant though the signs of the coefficients remain the same. The interaction term between heterogeneity in wealth and outside options, outside_diver is statistically significant and negative suggesting that conditional on the presence of wealth heterogeneity, heterogeneity in outside options has a negative effect on cooperation, and conditional on the presence of heterogeneity in outside options, wealth heterogeneity has a negative effect on cooperation.

The coefficient of the variable avgprop_use is positive and statistically significant. It suggests that with a rise in the absolute level of dependence on the forest, the motivation to collective manage the forest is high and hence the level of cooperation within the communities is also high. This implies that for policy purposes, community based natural resource management is likely to succeed in communities with higher dependence on the forest.

The signs of the other variables in the three specifications have the expected sign that do not change with a change in specification.

\section{Conclusions}

Discarding the 'tragedy of the commons' framework in favor of a view that local environmental issues are a problem of collective choice recognizes that communities are 
capable of creating and sustaining institutions related to natural resource management. However, there is much to be learned about the characteristics of these communities and how they affect cooperation. This paper focuses on one aspect of community (or group) characteristics, namely heterogeneity. It shows that heterogeneity is not unidimensional, that it has atleast three dimensions: wealth, social identity and interest in the resource. While these dimensions can overlap they affect cooperation differently.

The quadratic relationship between social heterogeneity and cooperation implies that the latter does not depend on parochialism. Socially heterogeneous communities are capable of achieving high levels of cooperation subject to the condition that there are no minority caste groups within the community. This suggests that when no caste group is in a minority position, they are less likely to socially excluded or discriminated against, and hence cooperation is high.

The quadratic relationship between wealth heterogeneity and cooperation suggest that there may be an optimal redistribution level that can be undertaken in order to achieve a higher level of cooperation. However, the negative interaction term between interest and wealth heterogeneity suggests that ability to contribute need not coincide with incentive to contribute; hence redistribution should be in favor of those who have a higher incentive to contribute to collective management.

Contrary to Olson's (1965) claim of the "exploitation of the great by the poor", the "great" users are not necessarily those with higher levels of wealth but those who benefit from and hence have an incentive to manage and conserve the natural resource. In the case of forest resources, wealth and interests do not coincide. Those with higher levels of resource dependence and lower access to outside options are likely to be the ones with a higher level of interest. Resource dependent users who may be poor members of the 
community are likely to contribute much more in forest management than the rich members of the community.

The results also suggest caution when implementing conservation-community development schemes. The schemes that create or accentuate existing differences in resource-dependence, access to alternative sources of income, and wealth can lead to divergence in the preferences of members. Rather than being beneficial, such policies could harm the objectives of forest conservation and community development.

Heterogeneity can thus have important social and ecological consequences and understanding both its nature and effects can help in neutralizing the negative and enhancing the positive (Schlager and Bloomquist, 1996). The complex nature of heterogeneity calls for a greater attention to how members in the community interact with each other given the socio-economic conditions and to the role of redistributive measures in order to correct for past inequities as well to ensure the smooth working of local institutions in maintaining and enhancing ecological and social well-being. 


\section{References}

Acheson, J.M. The Lobster Gangs of Maine. University Press of New England. 1988.

Adhikari, B. Property Rights and Natural Resource: Socio-Economic Heterogeneity and Distributional Implications of Common Property Resource Management, Second World Congress of Environmental and Resource Economists, June 24-27, 2002, Monterey, California, USA. 2002.

Agarwal, B. "Gender and command over property: A critical gap in economic analysis and policy in South Asia." World Development, 22(10):1455-78, 1994.

Agarwal, B. Participatory exclusions, community forestry, and gender: An analysis for South Asia and a conceptual framework. World Development, 29(10): 1623-47. 2001.

Agrawal, A., Gibson, C. C. "Enchantment and disenchantment: The role of community in natural resource conservation." World Development, 27.(4):629.-649, 1999.

Agrawal, A. Greener Pastures: Politics, Markets, and Community Among a Migrant Pastoral People. Durham, NC: Duke University Press, 1999

Agrawal, A. "Common property institutions and sustainable governance of resources." World Development, 29 (10): 1649-72, 2001.

Alesina, A., Baqir, R., Easterly, W. "Public Goods and Ethnic Divisions”, Policy Research Working Paper Series 2108. The World Bank. 1999

Alesina, A., La Ferrara, E. "Participation in Heterogeneous Communities," The Quarterly Journal of Economics, 115(3): 847-904. 2000.

Arnold, J.E.M. and M. Ruiz Perez. The Role of Non-timber Forest Products in Conservation and Development, pp17 - 42, in E Wollenberg \& A Ingles (eds.), Incomes from the forest: Methods for the development and conservation of forest products for local communities. CIFOR / IUCN. 1999

Baland, J.M. Bardhan, P. Das, S. Mookherjee, D. Sarkar, R. Inequality, collective action and the environment: evidence from firewood collection in Nepal. In Baland, J.M., Bardhan, P. Bowles, S. (eds). Inequality and Environmental Sustainability. (forthcoming).

Baland, J., Platteau, J. Coordination Problems in Local Level Resource Management. Journal of Development Economics, 53:197-210, 1996.

Baland, J. Platteau, J. The Ambiguous Impact of Inequality on Local Resource Management. World Development, 27(5): 773-88. 1999. 
Baland, J.M. and J.-P. Platteau. Institutions and the efficient management of environmental resources, In K. G. Mahler and J. Vincent (eds) Handbook of Environmental Economics , Elsevier, North Holland. 2003

Baland, J. Platteau, J. 2002. Collective action on the commons: the role of inequality. In Baland, J.M., Bardhan, P. Bowles, S. (eds). Inequality and Environmental Sustainability. (forthcoming).

Bardhan, P.K., Irrigation and cooperation: An empirical analysis of 48 irrigation communities in South India. Economic Development and Cultural Change, 48, 847-865. 2000 .

Bardhan, P., Dayton-Johnson, J. 'Heterogeneity and Commons management'. Proceedings of the $8^{\text {th }}$ International Conference on Common Property, IASCP. Bloomington, Indiana, May 31- June 4, 2000.

Bardhan, P. Dayton-Johnson, J. Inequality and governance of water resources in Mexico and South India. In Baland, J.M., Bardhan, P. Bowles, S. (eds). Inequality and Environmental Sustainability. (forthcoming).

Berkes, F. Fishermen and the "tragedy of the commons." Environmental Conservation 12:199-206. 1985.

Boyce, J.K. Inequality as a cause of environmental degradation. Ecological Economics, 11(3): 169-78, 1994.

Bowles, S., Gintis, H. "Social capital and Community Governance." The Economic Journal, 112: F419 -F436, 2002.

Cavendish, W. Empirical regularities in the poverty-environment relationship of rural households:evidence from Zimbabwe. World Development, 28(11):1979-2003, 2000.

Chhetri, R. B.; Pandey, T. R. User group forestry in the Far-Western region of Nepal: case studies from Baitadi and Achham. Kathmandu: International Centre for Integrated Mountain Development. 1992.

Chopra, K., Kadekodi, G.K. "Participatory Institutions: The context of common and private property resources” Environment and Development Economics, 1: 353-72.1991

Dayton-Johnson, J., Bardhan, P. "Inequality and Conservation on the Local Commons: A Theoretical Exercise”. The economic Journal, 112(July): 577-602, 2002.

Gadgil, M., Guha, R. Ecology and Equity: The Use and Abuse of Nature in Contemporary India. London: Routledge, 1995.

Gibson, C., McKean, M., Ostrom, E. "Explaining Deforestation: The Role of Local Institutions." in Gibson, C., McKean, Ostrom, E. eds., People and Forests: Communities, Institutions, and Governance. Cambridge, MA: MIT Press. 2000. 
Greenberg, S.H. The measurement of linguistic diversity. Language, 3:109 -115. 1956

Guha, R. The Unquiet Woods: Ecological Change And Peasant Resistance In The Himalaya Berkeley : University of California Press, 1990

Hechter, A. The attainment of solidarity in intentional communities. Rationality and Society, 2(2):142-155, 1990.

Jodha, N. S. "Common property resources and the environmental context: Role of biophysical versus social stresses." Economic.and Political.Weekly, 30(51): 1995.

Jodha, N. S. "Natural resource management and poverty alleviation in mountain areas: approaches and efforts. Conference Proceedings of the International Conference on Natural Assets, Jan $8^{\text {th }}-12^{\text {th }}$, 2003. Tagatay City, The Phillippines. 2002.

Kadekodi, G. K. Common Property Resource Management: Reflections on Theory and The Indian Experience. New York : Oxford University Press, 2004.

Kant, S. A Dynamic Approach to Forest Regimes in Developing Economies. Ecological Economics. 32(2000): 287-3000. 2000

Khwaja, A. I. Can Good Projects Succeed in Bad Communities? Collective Action in the Himalayas. Mimeo Boston: Department of Economics, Harvard University. 2000

Laitin, D. What is a Language Community? American Journal of Political Science 44(1):142-55. 2000.

LaFerrara, E. Inequality and Group Participation: Theory and Evidence from Rural Tanzania. IGIER (Innocenzo Gasparini Institute for Economic Research) Working Papers 161, Bocconi University 2000.

Marwell, G., Oliver, P. The Critical Mass In Collective Action: A Micro-Social Theory. New York, NY, USA : Cambridge University Press, 1993

McCay, B.J. "Common and Private Concerns”. In Hanna, S.S., Folke, C., Maler, K.G. eds. Ecological, Economic, Cultural, and Political Principles of Institutions for the Environment. Washington D.C.: Island Press, 1996.

Molinas, J.R. The Impact of Inequality, Gender, External Assistance and Social Capital on Local Level Cooperation. World Development, 26(3):413-431, 1998.

Olson, M. The Logic of Collective Action: Public Goods and the Theory of Groups. Mass: Harvard University Press, 1965

Ostrom, E. Governing the commons: the evolution of institutions for collective action. New York : Cambridge University Press, 1990. 
Ostrom, E. "The Institutional Analysis and Development Approach." In Designing Institutions for Environmental and Resource Management, eds. Edna Tusak Loehman and D. Marc Kilgour. Cheltenham, UK: Edward Elgar Publishing, 1998.

Peluso, N. C. Rich Forests, Poor People. Berkeley: University of California Press, 1992.

Poffenberger, $\mathrm{M}$ and C. Singh. Communities and the state: re-establishing the balance in Indian Forest Policy, in M., Poffenberger and B McGean, eds. Village Voices, Forest Choices: Joint Forest Management in India. Delhi: Oxford University Press, 1996.

Poteete, A., Ostrom, E. In Pursuit of Comparable Concepts and Data about Collective Action. CAPRi Working paper No. 29. 2003.

Reddy, S.R.C., Chakravarthy, S.P. Forest dependence and income distribution in subsistence economy: Evidence from India. World Development, 27(7): 1141- 49, 1999.

Richards, M., Kanel, K., Maharajan, M, Davies, J. Towards Participatory Economic Analysis by Forest User Groups in Nepal. London: Overseas Development Institute. 1999.

Ruiz- Perez, M., Byron, N. (eds) A Methodology to Analyse Divergent Case-Studies to Analyze Non-timber Forest Products and their Development Potential. Forest Science, 45(10: 1-14. 1999.

Schlager, E. \& Bloomquist, W. A Comparison of Three Emerging Theories of the Policy Process. Political Research Quarterly, 49(3), September, 1996, 651-72. 1996.

Steins, N. A. \& Edwards, V. M. Platforms for collective action in multiple-use commonpool resources. Agriculture and Human Values 16:241-55. 1999.

Wade, R. Village Republics: Economic Conditions For Collective Action In South India. New York : Cambridge University Press, 1988. 